\title{
The use of a multivariate analysis to study between-goat variability in feeding behavior and associated rumen $\mathrm{pH}$ patterns
}

\author{
M. Desnoyers, ${ }^{\star} \dagger$ S. Giger-Reverdin, ${ }^{*}{ }^{1}$ D. Sauvant, ${ }^{*} \dagger$ and C. Duvaux-Ponter ${ }^{\star} \dagger$ \\ *INRA, UMR791 Modélisation Systématique Appliquée aux Ruminants, 16 rue Claude Bernard, F-75005 Paris, France \\ †AgroParisTech, 16 rue Claude Bernard, F-75005 Paris, France
}

\begin{abstract}
This study examined feeding patterns and their relation to rumen $\mathrm{pH}$. The measured variables were the cumulative time spent chewing (eating or ruminating) and the mean rumen $\mathrm{pH}$, per 20-min intervals (46 intervals altogether). A total of 333 feeding patterns, defined as time-series of measurements for 1 animal and 1 given day during $15 \mathrm{~h}$ and $20 \mathrm{~min}$ following the afternoon feeding, were collected from 12 stall-housed dairy goats fed a total mixed ration twice daily. The first objective of this study was to analyze the within-day variability of feeding behavior to characterize different feeding patterns. The second objective was to analyze, for each goat, the between-day variability of its feeding behavior. The third objective was to study the influence of feeding behavior on rumen $\mathrm{pH}$. A multivariate method (principal component analysis) was performed on the time spent eating or ruminating during each of the 46 intervals. The factor score plots generated by the principal component analysis highlighted the evolution in time of chewing activities. They also were used to determine 4 different types of feeding behavior in the extreme patterns of the first 2 axes. These feeding patterns were associated with different rumen $\mathrm{pH}$ patterns in goats with the same total dry matter intake and mean rumen $\mathrm{pH}$. Some goats had a major eating period immediately after feeding, followed by a period of rumination; this pattern was associated with a marked decrease in rumen $\mathrm{pH}$ and a $\mathrm{pH}$ nadir below 6.0. Other goats performed alternate periods of eating and ruminating throughout the studied period. The latter feeding pattern was associated with a shorter total duration of rumination, but a more stable rumen $\mathrm{pH}$ than the feeding pattern described previously. Feeding pattern was quite constant between days for some goats, but highly variable for others. However, the continuum observed between these 4 groups shows that many intermediate types of behavior can be observed. In conclusion, char-
\end{abstract}

Received May 22, 2010.

Accepted October 27, 2010.

${ }^{1}$ Corresponding author: sylvie.giger-reverdin@agroparistech.fr acterizing animals according to their feeding behavior by using a principal component analysis may provide information on the animal's predisposition to rumen acidosis.

Key words: between-animal variability, dairy goat, patterns of chewing behavior and rumen $\mathrm{pH}$, principal component analysis

\section{INTRODUCTION}

Feeding behavior includes 3 steps: foraging, feed selection and intake, and its related activity, rumination (Jarrige et al., 1995). In intensive systems, foraging and feed selection are limited to domestic ruminants, but numerous factors other than hunger and satiety can still influence feeding behavior. Stall-housed ruminants fed ad libitum eat most of their daily allowance during daylight, with 2 peaks at sunset and sunrise (Dulphy and Faverdin, 1987). In dairy cows fed once daily at $0800 \mathrm{~h}$, the largest percentage of feed was eaten during the first $3 \mathrm{~h}$ after feeding, whereas the least amount of feed was eaten $14 \mathrm{~h}$ after feeding (i.e., during the night when the feed was offered in the morning; Heinrichs and Conrad, 1987). Rumination, which is stimulated by fibrous material in the rumen (Welch and Smith, 1971), is usually observed at night, in the early morning, and in late afternoon in ruminants fed twice daily (Beauchemin et al., 1990; Deswysen et al., 1993; Fischer et al., 2002).

It is well known that feeding behavior can be influenced by parameters characterizing the animal (e.g., age, weight, physiological stage) and by the level of production (Albright, 1993; Jarrige et al., 1995). However, Dulphy et al. (1990) observed greater differences in feeding behavior between ruminants from the same species than between different species and a greater variability in small ruminants (sheep and goats) than in cattle. Jarrige et al. (1995) observed that dairy cows of similar BW, DMI, and milk yield could present different feeding patterns and intake rates. The cow that had the highest intake rate had the greatest changes in rumen parameters, especially a greater decrease in rumen $\mathrm{pH}$, which could reduce microbial activity in the rumen (Jarrige et al., 1995). 
Feeding a high-concentrate diet to ruminants to meet their nutritional requirements can induce subacute rumen acidosis and is often associated with off-feed periods (Nocek, 1997; Oetzel, 2000). Meal size and frequency may be important factors influencing the $\mathrm{pH}$ decline and, consequently, the occurrence of subacute ruminal acidosis (Allen, 1997; Krause and Oetzel, 2006). However, it is not clear whether rate of digestion or feeding behavior is the driving force because each is affected by the other.

Feeding behavior patterns were analyzed using a shorter time scale than $24 \mathrm{~h}$ to better understand variations in feeding behavior. The first objective of this paper was to analyze the within-day variability in feeding behavior to characterize different types of feeding behavior in stall-housed dairy goats fed twice daily. The second objective was to analyze, for each goat, the between-day variability of its feeding behavior. The third objective was to determine if the differences in feeding behavior could influence the within-day evolution of rumen $\mathrm{pH}$, particularly in relation to the occurrence of subacute ruminal acidosis.

\section{MATERIALS AND METHODS}

The present study was carried out according to French legislation on animal experimentation in line with the European Convention for the Protection of Vertebrates used for Experimental and other Scientific Purposes (European Directive 86/609).

\section{Animals and Housing}

The trial was conducted in 12 ruminally cannulated dairy goats (4 Saanen and 8 Alpine; $40 \pm 4.0$ DIM, 65 $\pm 7.4 \mathrm{~kg}$ of BW, $3.5 \pm 0.58 \mathrm{~kg}$ of milk/d at the start of the experiment) and lasted 11 wk. Goats were housed in $2 \mathrm{~m} \times 1 \mathrm{~m}$ individual pens with free access to water. They were fed a TMR ad libitum (Table 1) and quantities of feed offered were adjusted weekly to ensure $10 \%$ refusals. Feed was offered individually twice a day after milking, in the proportion of two-thirds of the daily total at $16 \mathrm{~h}$ and one-third at $8 \mathrm{~h}$ according to the intervals between milkings. The energy value of the diet was calculated according to the analytical method proposed by Vermorel (1988), taking into account the digestive interactions due to both feeding level and proportion of concentrate in the diet (Sauvant and Giger-Reverdin, 2007). The nitrogen value of the diet was calculated according to the additive method from the INRA tables (Baumont et al., 2007).

\section{Weight and Feed Intake}

Animals were weighed weekly. Individual amounts of feed offered and refusals were weighed daily, which
Table 1. Composition and analysis of the experimental diet

\begin{tabular}{lc}
\hline Item & Amount \\
\hline Composition $\left(\%\right.$ of DM) $^{1}$ & \\
Concentrate blend $^{1}$ & 50 \\
Grass hay & 35 \\
Sugar beet pulp & 15 \\
DM (\%) & 63 \\
Net energy (MJ/kg of DM) & 6.48 \\
PDIN ${ }^{2}$ (g/kg of DM) & 95 \\
PDIE (g/kg of DM) & 103 \\
Analysis, \% of DM & \\
NDF & 34.7 \\
ADF & 15.9 \\
Acid detergent lignin & 1.8 \\
Ash & 6.4 \\
CP & 12.7 \\
Enzymatic starch & 16.5 \\
\hline
\end{tabular}

${ }^{1}$ Concentrate blend $=25 \%$ wheat, $25 \%$ barley, $30 \%$ maize, $15 \%$ soybean meal, $3 \%$ molasses, and $2 \%$ mineral premix (8\% P, $25 \%$ Ca, $4 \%$ $\mathrm{Mg})$.

${ }^{2} \mathrm{PDIN}=$ true protein digested in the small intestine when fermentable $\mathrm{N}$ is limiting; PDIE = true protein digested in the small intestine when fermentable energy is limiting; PDIN and PDIE are calculated from the INRA tables (Baumont et al., 2007).

allowed for assessment of DMI using the DM percentage of the diet that was estimated weekly from water content (ISO, 1983). The DMI per kilogram of BW was calculated using the BW of the previous week.

\section{Continuous Measurements}

During the week before the beginning of the experiment, each goat was accustomed to wearing a coat covering its back, maintained by individually adjusted elastic straps and an adjustable leather halter especially designed for goats (Desnoyers et al., 2009a). Rumen $\mathrm{pH}$ was measured every minute by a self-cleaning $\mathrm{pH}$ probe (accuracy $=0.01 \mathrm{pH}$, Fisher Bioblock Scientific, Illkirch Graffenstaden, France) fitted in the rumen with a ruminal cannula and linked to a portable device (Easy Log EL-2, Omega Engineering Inc., Stamford, CT; Brossard et al., 2003) placed in one of the coat pockets. A 300-g weight was attached to each probe to reduce its mobility in the rumen. Because of some technical problems, $\mathrm{pH}$ was not measured every day in every goat. Thus, a variable number of days was missing for each goat. Chewing activity was recorded using an automatic portable system (APEC) adapted from the 1 used by Brun et al. (1984) and placed in another coat pocket. The APEC data files were analyzed by a specific software package written at INRA Theix (France) that classified periods of chewing activity as ruminating, eating, or jaw resting. An eating or a ruminating period was a period exceeding $7 \mathrm{~min}$, during which the animal maintained the same activity (including any short pauses in jaw movements of less than 7 
min; Desnoyers et al., 2009a). The program computed the total duration of each activity and the net durations by excluding the pauses. This software was modified by C. Reverdin to allow the calculation of the time spent in each activity every 2 min instead of one hour with the initial version. A single feeding pattern was defined as the time series of measurements of eating and ruminating for 1 animal and 1 given day during 15 $\mathrm{h}$ and $20 \mathrm{~min}$ following the afternoon feeding. A total of 333 feeding patterns was available for the 12 goats, which meant that a goat would provide approximately $28 \mathrm{~d}$ of measurements. For 2 goats, only $17 \mathrm{~d}$ were available, and for 1, 43 patterns were complete. Around two-thirds of the feeding patterns (216 out of 333) were obtained on Alpine goats, which was consistent with the ratio between breeds in our experiment. Data on chewing activity and rumen $\mathrm{pH}$ were merged for every goat in 1 data set, which included every minute of the experiment cumulative time spent eating, ruminating, and jaw resting, and rumen $\mathrm{pH}$, when available.

\section{Analysis}

Only data obtained between the afternoon feeding, just after the afternoon milking, and the next morning feeding were used ( $15 \mathrm{~h} 20 \mathrm{~min}$ ) because two-thirds of the total daily feed were offered in the afternoon. Moreover, during this part of the day, goats were not disturbed by the activity in the experimental facility. Every 20 min after the afternoon feeding (forty-six 20min intervals altogether), eating, ruminating, and resting durations were summed up and $\mathrm{pH}$, when available, was averaged. A principal component analysis (PCA) was performed on the cumulative time spent eating and the cumulative time spent ruminating within each of the forty-six 20-min intervals (sequentially numbered from time of afternoon feeding) and obtained from the 333 feeding patterns. The objective of a PCA is to synthesize the overall information contained in a set of observed variables into a smaller number of linear combinations of orthogonal variables called principal components (PC). The PC sequentially minimize the remaining variation in the multivariate data space. Thus, the PCA condenses the information into loadings that show the relative importance (weighting) of the original variables in accounting for the variability in the observed data. The distribution of the observed data across the PC is shown by the scores. A total of 92 variables were included in the PCA. Ten percent of the patterns to the extreme right and to the extreme left of each of the first 2 PC axes were selected and analyzed separately to study directly the range of eating patterns (e.g., large meals vs. small meals and longer vs. shorter rumination times).
To study within-goat variability of feeding behavior, as goats were not equally represented in the initial data set, their occurrences in the extreme groups were weighted by the inverse of their occurrence in the initial data set.

\section{RESULTS}

Time spent eating and ruminating in 20-min intervals for the 333 feeding patterns showed that feeding was followed by a period of intense intake lasting approximately $1 \mathrm{~h}$ (Figure 1). A short rumination period was observed before the end of the second hour after feeding. This rumination period was followed by another eating period and then the time spent ruminating increased until early morning at the expense of eating and jaw resting. A final eating period occurred in the early morning approximately $1 \mathrm{~h}$ before feeding.

\section{Principal Component Analysis on the Time Spent Eating and Ruminating}

The first 2 components of the PCA explained $11.3 \%$ of the total variance (Figure 2), which is reasonable in relation to the high number of variables used (92). For the first component, an inverse relationship was observed between the time spent eating and the time spent ruminating, especially during the first 8 intervals $(8 \times 20=160 \mathrm{~min}=2 \mathrm{~h} 40 \mathrm{~min})$. For this first component, an inverse relationship was also observed between the time spent eating during the intervals 1 to 8 and the time spent eating during the intervals 10 to 17 (Figure 2). The evolution of the time spent ruminating was globally symmetrical to the evolution of the time spent eating. The second component showed a secondary pattern, overlapping the 1 defined by the first component. This secondary pattern showed an inverse relationship between the time spent eating during the intervals 1 and 2 and the time spent eating during the intervals 5 and 6 , as well as an inverse relationship between the time spent eating during the intervals 10 to 14 and the time spent eating during the rest of the day. Similarly, time spent ruminating during the first 2 intervals varied inversely compared to the time spent ruminating during the intervals 4 to 6 , and to the time spent eating during the first 2 intervals.

The projections of the 333 feeding patterns on the first 2 components, encoded according to the goat, showed that the patterns for a given goat were close together (Figure 3). Mean values for different goats were found in different sectors of the scores plot, indicating clear between-goat differences in feeding behavior patterns. However, the standard errors were variable between goats. Moreover, the projections of the feeding 


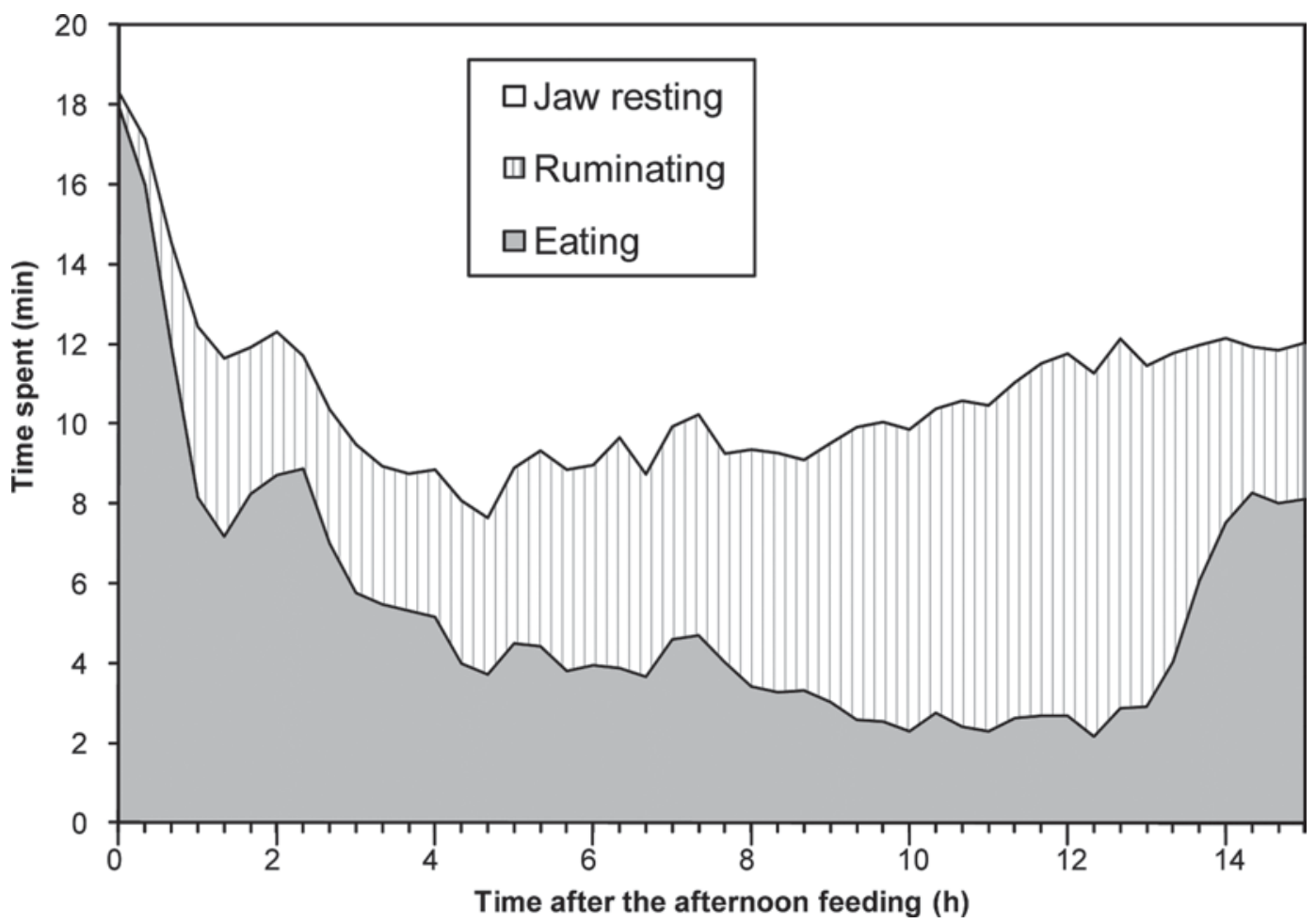

Figure 1. Percentage of time spent eating, ruminating, or jaw resting in 20-min intervals during the $15 \mathrm{~h}$ and 20 min following the afternoon feeding (333 feeding patterns).

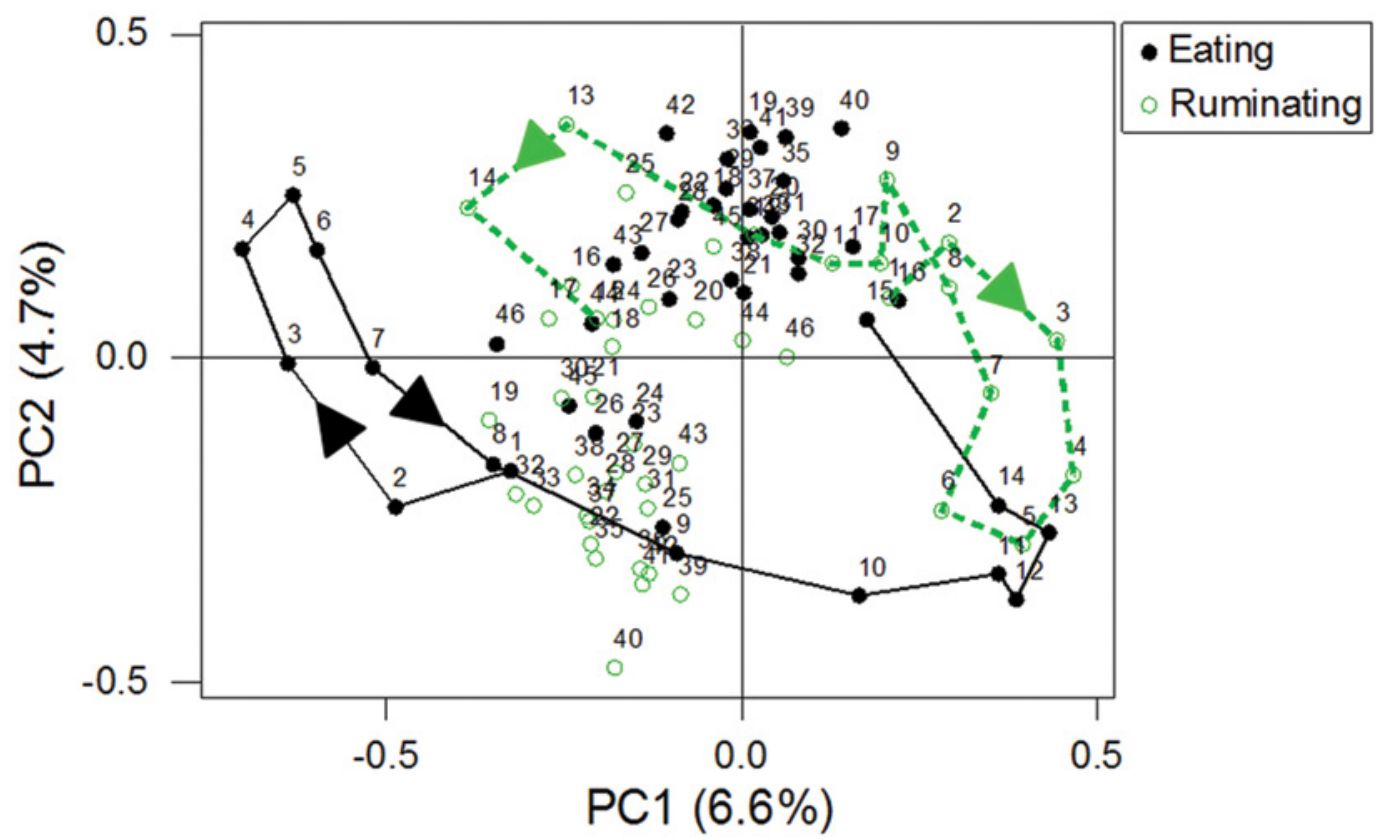

Figure 2. Results of a principal component analysis based on time spent eating and time spent ruminating during each of the forty-six 20min intervals following the afternoon feeding obtained in 333 feeding patterns, presented as a loading plot of the 92 variables. The percentage of total variance accounted for by each of the first 2 principal components (PC) is shown in parentheses. The 46 numbers in the graph show the evolution in time of the different intervals and the lines join the first 15 intervals $(5 \mathrm{~h})$ for each chewing activity. Color version available in the online PDF. 


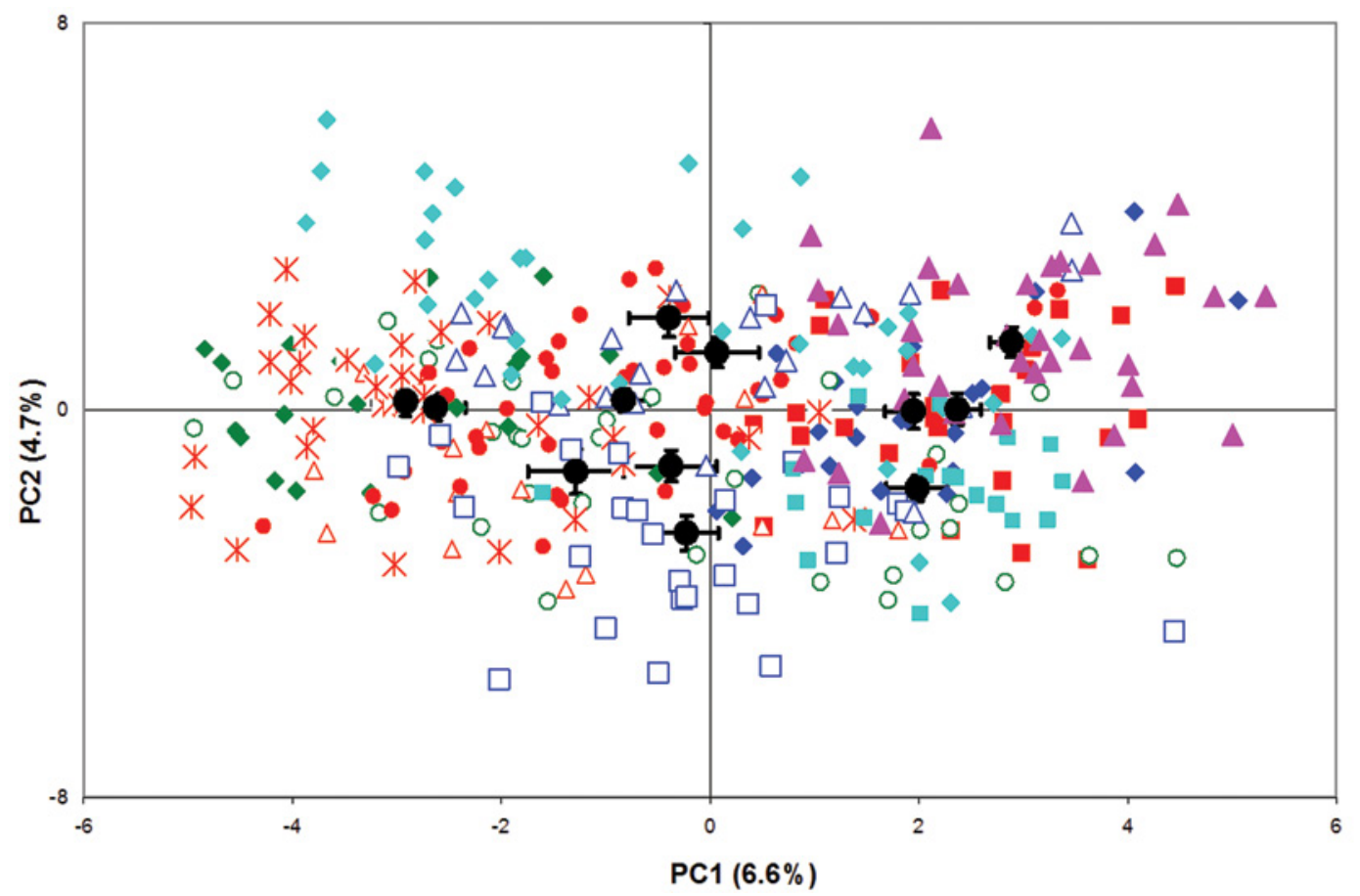

Figure 3. Results of a principal component (PC) analysis based on the time spent eating and the time spent ruminating during each of the forty-six 20-min intervals following the afternoon feeding obtained in 333 feeding patterns, presented as a score plot of 12 goats. Means (-) and standard errors of PC 1 and 2 are represented for each of the 12 goats (each goat is represented by a specific symbol). Color version available in the online PDF.

patterns were evenly distributed across the scores plot for the first $2 \mathrm{PC}$, indicating a continuum of feeding pattern types.

\section{Characterization of Typical Feeding Behavior}

The 33 feeding patterns situated at the extreme left and extreme right of each PC axis were selected for further analyses. One of the 2 extreme groups (group 1A) of the first axis presented a large first period of intake after feeding, followed by increasing rumination during the night until a new period of intake in the early morning (Figure 4). The other extreme group of the first axis (group 1B) presented a relatively short first period of intake after feeding, followed by a rumination period and then a second major period of intake 3 to $5 \mathrm{~h}$ after feeding (Figure 4). Later, this group presented alternate eating and ruminating periods during the night and the early morning. During the $15 \mathrm{~h}$ analyzed, the goats spent more time eating in group $1 \mathrm{~A}$ than in group $1 \mathrm{~B}(5 \mathrm{~h} 00 \pm 10 \mathrm{~min}$ and $3 \mathrm{~h} 29 \pm 10 \mathrm{~min}$ for groups $1 \mathrm{~A}$ and $1 \mathrm{~B}$, respectively; $P<0.001$ ) and more time ruminating ( $4 \mathrm{~h} 30 \pm 13 \mathrm{~min}$ and $3 \mathrm{~h} 01 \pm 13 \mathrm{~min}$, for groups $1 \mathrm{~A}$ and $1 \mathrm{~B}$, respectively; $P<0.001$ ). Therefore, the goats of group $1 \mathrm{~A}$ spent more time chewing (eating and ruminating) than the goats of group 1B (9 h $30 \pm$
16 min and $6 \mathrm{~h} 30 \pm 16 \mathrm{~min}$, for groups $1 \mathrm{~A}$ and $1 \mathrm{~B}$, respectively; $P<0.001$ ).

Two different feeding behaviors also were characterized on the second PC axis (Figure 5). One group (group 2A) showed a splitting of the first eating period following feeding into 2 eating bouts separated by rumination. The goats of this group then performed a long period of rumination during the night disrupted by a few short periods of intake, and started a new period of intake in the early morning. The other group (group 2B) presented alternate periods of eating and ruminating until the next feeding. The goats of group $2 \mathrm{~A}$ spent less time eating than the goats of group $2 \mathrm{~B}$ (4 $\mathrm{h} 00 \pm 11 \mathrm{~min}$ and $5 \mathrm{~h} 08 \pm 11 \mathrm{~min}$, for groups $2 \mathrm{~A}$ and 2B, respectively; $P<0.001$ ) and more time ruminating (4 h $36 \pm 10 \mathrm{~min}$ and $3 \mathrm{~h} 21 \pm 10 \mathrm{~min}$, for groups $2 \mathrm{~A}$ and $2 \mathrm{~B}$, respectively; $P<0.001$ ). The goats of these 2 groups spent on overall the same time chewing (eating + ruminating: $8 \mathrm{~h} 36 \pm 17 \mathrm{~min}$ and $8 \mathrm{~h} 29 \pm 17 \mathrm{~min}$, for groups $2 \mathrm{~A}$ and $2 \mathrm{~B}$, respectively; $P>0.1$ ), but with different patterns.

\section{Within-Goat Variability of Feeding Behavior}

As goats were not equally represented in the initial data set, their occurrences in the extreme groups were 

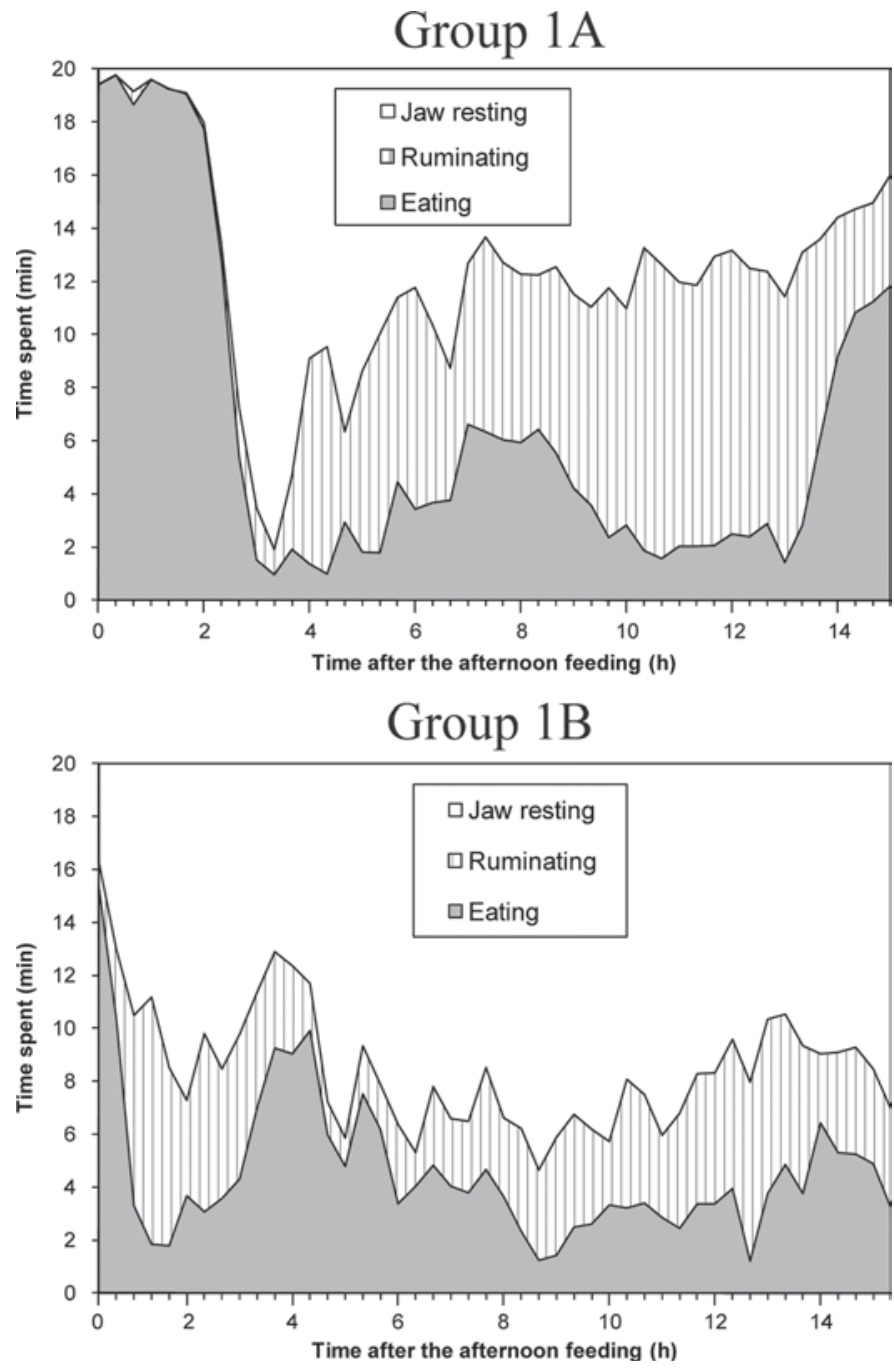

Figure 4. Mean values for time spent eating, ruminating, or jaw resting in 20-min intervals during the $15 \mathrm{~h}$ and 20 min following the afternoon feeding for the 33 patterns ( $10 \%$ of the total) situated at the extreme left (1A) and the extreme right (1B) of the first axis of the principal component analysis based on the time spent eating and the time spent ruminating during each of the forty-six 20-min intervals following the afternoon feeding obtained in 333 feeding patterns.

weighed by the inverse of their occurrence in the initial data set. For each of the 4 groups presented, 1 or 2 goats generally represented more than half of the 33 feeding patterns used to define the groups (Figure 6). In each group, 1 goat represented more than one-third of the total: goat 4 in group $1 \mathrm{~A}$, goat 12 in group $1 \mathrm{~B}$, goat 8 in group 2A, and goat 10 in group 2B. However, some goats, for example goats 7 and 10, were represented in the 4 groups.

\section{Feeding Behavior and Rumen $\mathrm{pH}$}

Within the 4 groups, patterns that included data for rumen $\mathrm{pH}$ were further analyzed. Time spent chew- ing and rumen $\mathrm{pH}$ patterns are presented in Figure 7. The pattern of eating and ruminating activities was similar to that of the whole groups, showing that these subgroups were representative of the whole groups presented in Figures 4 and 5. The goats of group 1A, which had a pronounced first period of intake followed by a major night rumination, presented a decrease in rumen $\mathrm{pH}$ after feeding. The mean rumen $\mathrm{pH}$ of group $1 \mathrm{~A}$ decreased quickly and remained below 6.0 for a long time. The threshold $\mathrm{pH}$ commonly used to define an acidosis incidence in lactating ruminants is 6.0 as it is the threshold under which feed degradation is impaired in the rumen (Oetzel, 2000). For the 23 goats in group $1 \mathrm{~A}$ with simultaneous $\mathrm{pH}$ and chewing patterns, the mean length of time during which the $\mathrm{pH}$ was below the critical value of 6.0 was $127( \pm 22.3)$ min in the first $6 \mathrm{~h}$ following feeding. The goats of group 1B, showing alternate eating and ruminating periods, presented a stable rumen $\mathrm{pH}$, with a mean value that was always higher than 6.0. For the 13 goats of this group, the mean length of time during which the rumen $\mathrm{pH}$ in the first $6 \mathrm{~h}$ following feeding was below 6.0 was lower (24 min \pm 6.6$)$ than for group 1A $(P=0.002)$. Despite these differences in rumen $\mathrm{pH}$ patterns and in rumen $\mathrm{pH}$ nadir (5.90 and 6.03, for groups $1 \mathrm{~A}$ and $1 \mathrm{~B}$, respectively), mean rumen $\mathrm{pH}$ and mean daily DMI were not significantly different between the 2 groups (Table 2). Total time spent eating and ruminating was greater for group 1A, which presented a marked first period of intake followed by a major night rumination compared with group 1B.

Similar results were observed on the second axis (Figure 7). The goats of groups $2 \mathrm{~A}$ and $2 \mathrm{~B}$ ate a similar quantity of feed. However, the goats of group 2A, which presented clearly identified eating and ruminating periods, showed a greater decrease in rumen $\mathrm{pH}$ with a lower $\mathrm{pH}$ nadir (5.68) than the goats of group $2 \mathrm{~B}(\mathrm{pH}$ nadir $=5.85)$, which presented alternate eating and ruminating periods. The goats from group $2 \mathrm{~A}$ spent more time ruminating than the goats of group $2 \mathrm{~B}$, but presented similar mean rumen $\mathrm{pH}$ (Table 3). On the second axis, it seemed that a substitution occurred between the 2 chewing activities (intake and rumination) as goats from group $2 \mathrm{~A}$ spent less time eating than goats from group $2 \mathrm{~B}$, whereas the time spent chewing was the same for the 2 groups (8:52 and 9:02 $\mathrm{h}$ for groups $2 \mathrm{~A}$ and $2 \mathrm{~B}$, respectively).

\section{DISCUSSION}

The use of a PCA allowed us to characterize 4 typical feeding behaviors in stall-housed dairy goats fed the same TMR and at the same physiological stage. This TMR, which contained only $35 \%$ grass hay, can induce 

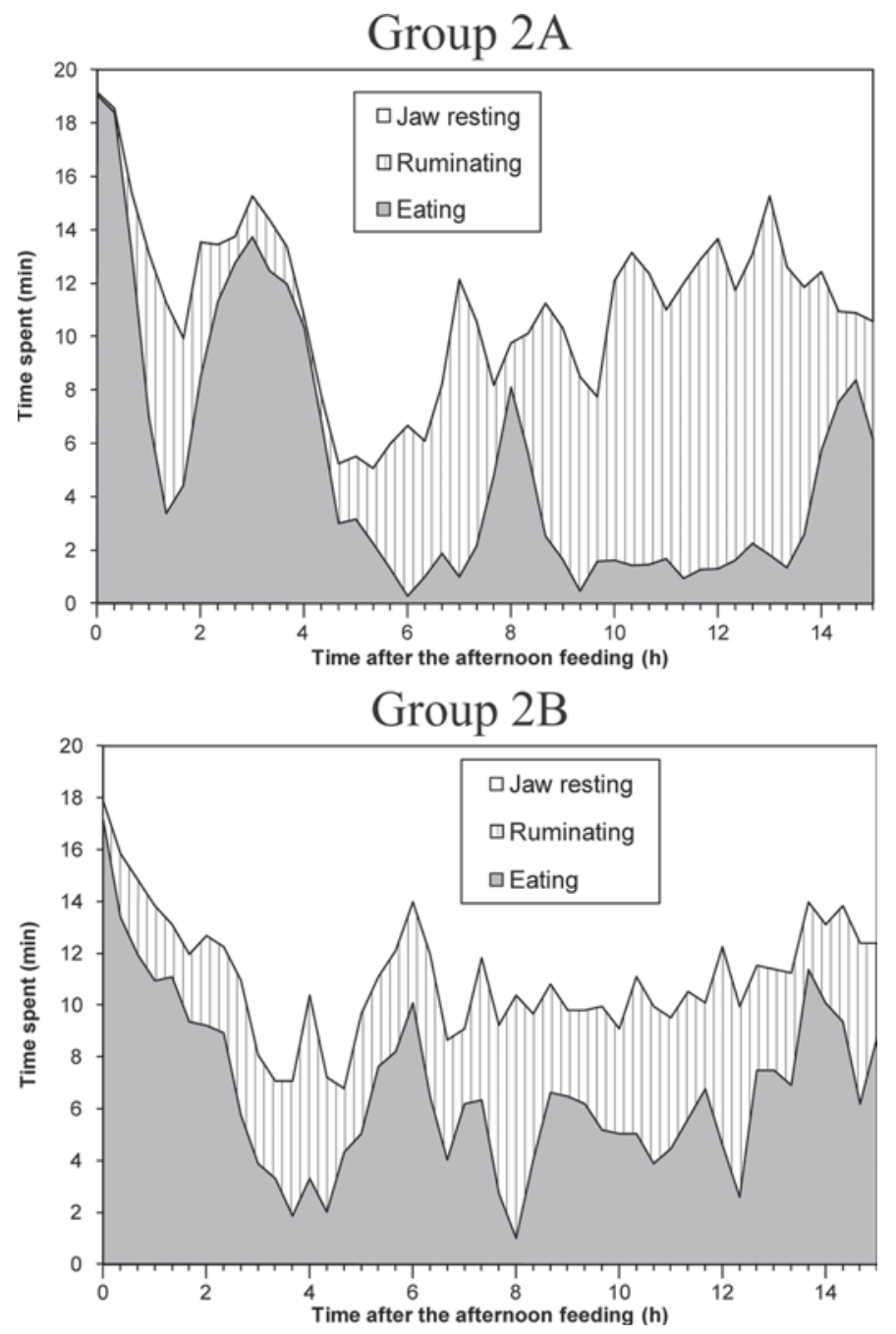

Figure 5. Mean values for time spent eating, ruminating, or jaw resting in 20-min intervals during the $15 \mathrm{~h}$ and $20 \mathrm{~min}$ following the afternoon feeding for the 33 patterns ( $10 \%$ of the total) situated at the extreme left $(2 \mathrm{~A})$ and the extreme right $(2 \mathrm{~B})$ of the second axis of the principal component analysis based on the time spent eating and the time spent ruminating during each of the forty-six 20-min intervals following the afternoon feeding obtained in 333 feeding patterns.

spontaneous acidosis in goats, as already shown in our laboratory (Desnoyers et al., 2009b). Some goats had a large first period of intake followed by long periods of rumination, whereas other animals alternated eating and ruminating periods. The feeding behavior observed in groups $1 \mathrm{~A}$ and $2 \mathrm{~A}$ (long periods of eating or ruminating) is in agreement with the literature describing a main meal after each feeding, separated by short secondary meals (Abijaoudé et al., 2000) and a main ruminating period during the night (Beauchemin et al., 1990; Deswysen et al., 1993; Fischer et al., 2002). This contrasts with the feeding behavior of groups $1 \mathrm{~B}$ and 2B. However, the continuum observed between these 4 groups shows that many intermediate types of behav- ior, between those described, can be observed. On each PC axis, different feeding patterns were highlighted, although total DMI was similar. This is in accordance with the work of Jarrige et al. (1995), who observed that dairy cows with similar daily DMI rate could present a 2-fold difference in instantaneous intake rate at the beginning of the meal. This also confirms that a very high degree of variation exists among animals within a herd in feeding behavior (because the feeding patterns of a given goat were grouped together on the scores plot of the first $2 \mathrm{PC}$, and this variability was not dependent on the daily DMI or on the daily milk production, which is highly correlated to DMI). Studying within-day variations in rumination patterns is not a new topic (Murphy et al., 1983). However, our approach allowed us to find more differences in feeding patterns than have been found in previous work.

Individual representation of the goats showed that each goat was preferentially represented in 1 part of the scores plot of the first $2 \mathrm{PC}$ axes of the PCA. Furthermore, the goats that had a mean score far from the center of the plot seemed to present lower standard errors than goats with a mean score near the center of the plot. Analysis of the contribution of the goats to the extreme groups confirmed that a high between- and within-goat variability occurred. Some goats performed the same type of feeding behavior during the whole experiment and were thus mainly represented in 1 group and in 1 part of the plot, far from the center, whereas other goats modified their feeding patterns during the experiment and were thus represented successively in the 4 groups and therefore near the center of the plot.

The animals that had a major first period of intake followed by a marked period of rumination (groups 1A and $2 \mathrm{~A}$ ) always spent more time ruminating than the animals from the groups that had alternating eating and ruminating periods (groups $1 \mathrm{~B}$ and $2 \mathrm{~B}$ ). In contrast, the time spent eating was not always influenced by the differences in feeding behavior. Mean rumen $\mathrm{pH}$ was not influenced by feeding behavior, despite differences in rumen $\mathrm{pH}$ patterns and in rumen $\mathrm{pH}$ nadir, a finding confirmed by Woodford and Murphy (1988). Despite a similar mean rumen $\mathrm{pH}$, grouping goats according to feeding behavior type revealed that different rumen $\mathrm{pH}$ patterns also occurred. The goats of group $2 \mathrm{~A}$, which had long periods of intake followed by long ruminating periods, presented greater rumen $\mathrm{pH}$ drops after feeding than the goats of group $2 \mathrm{~B}$ that had alternate eating and ruminating periods with the same high daily DMI (44 g of DM/kg of BW). This result suggests that the decrease in rumen $\mathrm{pH}$ and the amplitude of rumen $\mathrm{pH}$ drop were mainly dependent on the rate of intake or the quantity of feed eaten during the first hours following feeding. The high chewing duration of 


\section{Contribution of the goats to group $1 \mathrm{~A}$}

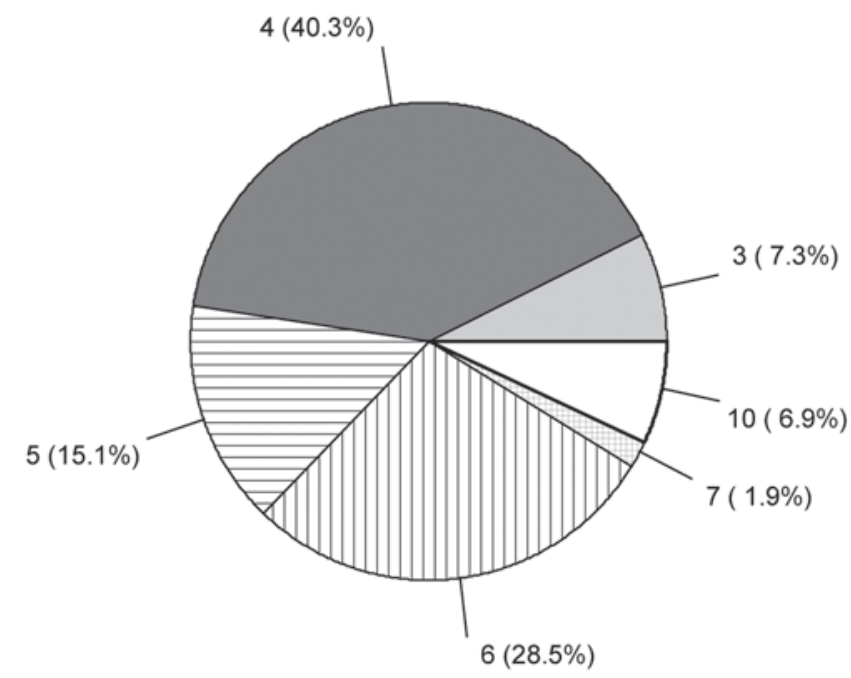

\section{Contribution of the goats to group $2 \mathrm{~A}$}

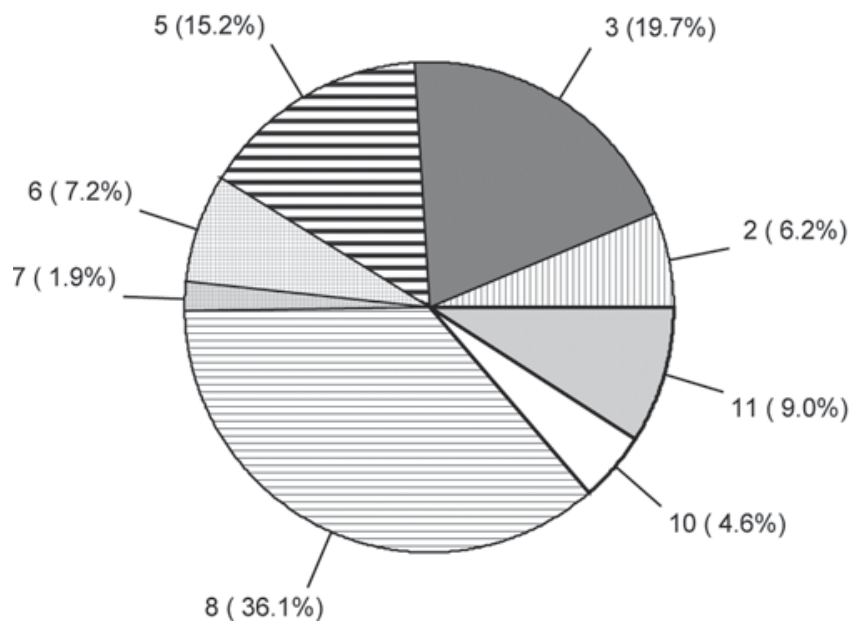

Contribution of the goats to group 1B

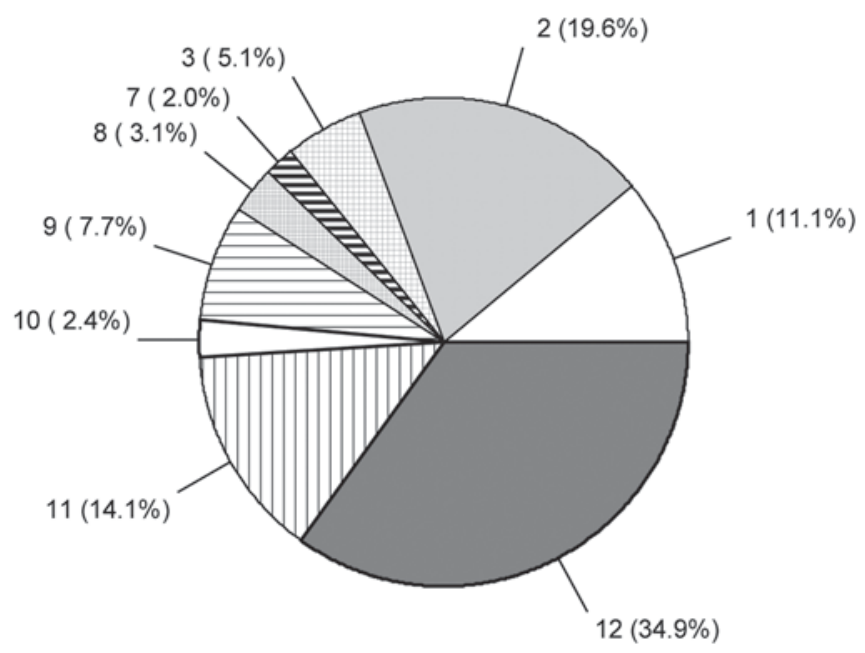

Contribution of the goats to group $2 \mathrm{~B}$

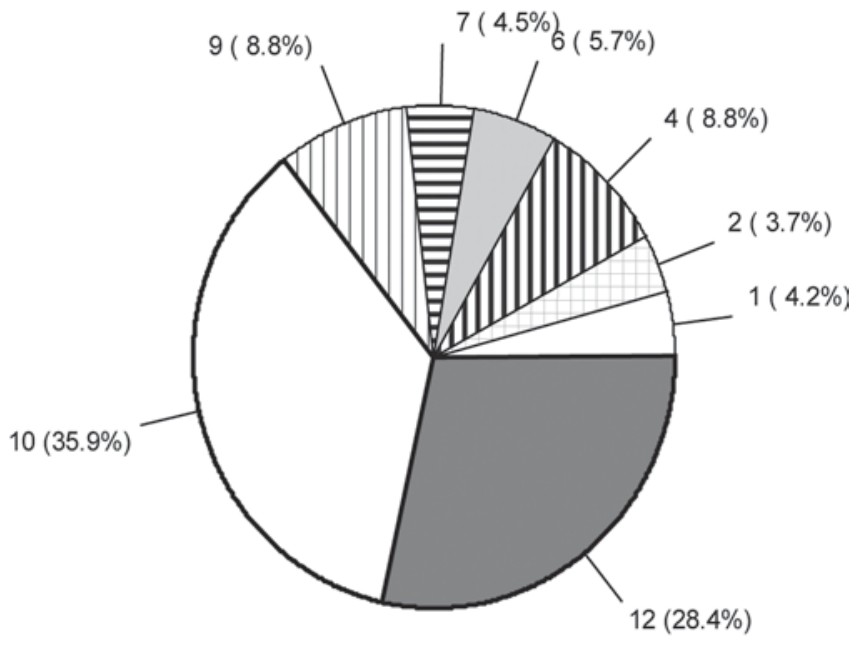

Figure 6. Relative contribution (in parentheses) of the 12 goats (identified in each pie chart by numbers 1 to 12 ) to the 4 groups of patterns situated at the extremities of the first 2 axes of the principal component analysis based on the time spent eating and the time spent ruminating during each of the forty-six 20-min intervals following the afternoon feeding obtained in 333 feeding patterns.

these animals during the evening and the night can be assumed to have led to a greater amount of saliva and buffers secreted into the rumen at this time in the $24 \mathrm{~h}$ cycle (Owens et al., 1998; Maekawa et al., 2002). This probably induced the important increase in rumen $\mathrm{pH}$ during the night. However, considering that the production of saliva during rumination is similar between animals (Putnam et al., 1966), the greater total amount of saliva produced by the goats of this group $2 \mathrm{~A}$ might not have been sufficient to limit the subsequent decrease in rumen $\mathrm{pH}$. The animals that ate quickly during the first period of intake certainly had a quicker and more marked increase in fibrous material in the rumen than the animals showing alternate eating and ruminating periods. Because rumination is stimulated by the presence of fibrous material in the rumen (Welch and Smith, 1971), this can explain the longer duration of rumination thereafter. This also might explain why a large first period of intake in the afternoon is always associated with a large ruminating period during the night.

Animals with long periods of intake followed by long ruminating periods might be more susceptible to acidosis because their rumen $\mathrm{pH}$ can decrease below 6.0 
Table 2. Daily DMI and mean rumen $\mathrm{pH}$, time spent eating, and time spent ruminating $15 \mathrm{~h}$ and $20 \mathrm{~min}$ after feeding, when $\mathrm{pH}$ data were available, in 2 groups of goats defined as being the left extreme (group 1A) or the right extreme (group 1B) on the first axis of a principal component analysis of cumulative eating and ruminating time

\begin{tabular}{lcccc}
\hline Item & $\begin{array}{c}\text { Group } \\
1 \mathrm{~A}\end{array}$ & $\begin{array}{c}\text { Group } \\
1 \mathrm{~B}\end{array}$ & $\begin{array}{c}\text { Root mean } \\
\text { square error }\end{array}$ & $P$-value \\
\hline Feeding patterns with pH data (no.) & 23 & 13 & & \\
DMI (g/kg BW) & 39.6 & 36.2 & 8.62 & $\mathrm{NS}$ \\
Mean rumen pH & 6.07 & 6.21 & 0.314 & $\mathrm{NS}$ \\
Time spent (h:min) & & & & \\
Eating & $04: 47$ & $03: 43$ & $00: 48$ & 0.001 \\
Ruminating & $04: 34$ & $03: 39$ & $00: 57$ & 0.009 \\
\hline
\end{tabular}

or 5.5 for a few hours, as observed for the goats from groups $1 \mathrm{~A}$ and $2 \mathrm{~A}$. These goats spent approximately $1 \mathrm{~h}$ more ruminating than goats from groups $1 \mathrm{~B}$ and 2B. However, this is not in accordance with the results of Beauchemin et al. (2003), who showed that increasing ruminating time rather than increasing eating time may be more efficient for improving ruminal $\mathrm{pH}$ status. The increase in ruminating duration in the experiment
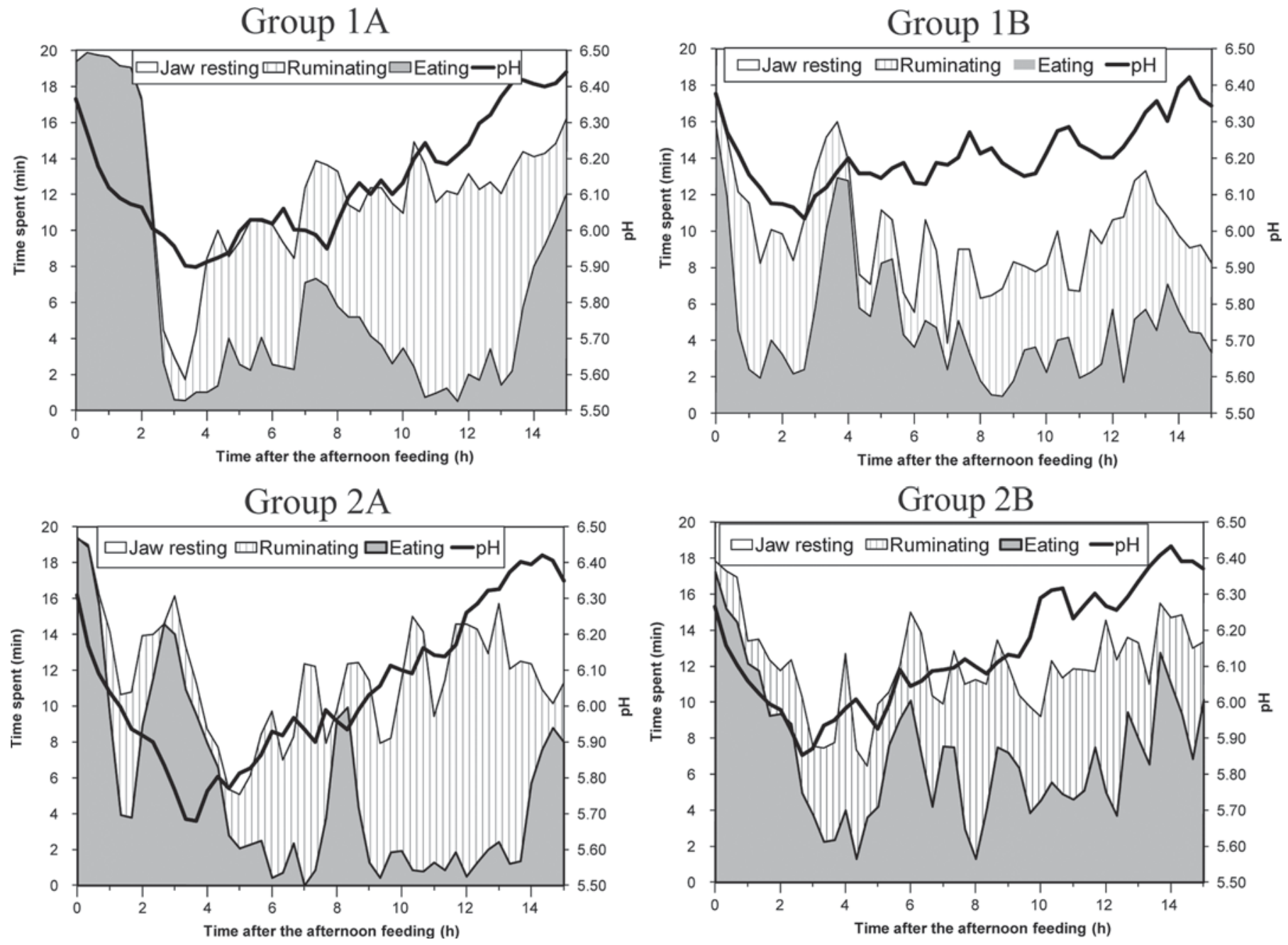

Figure 7. Time spent eating, ruminating, or jaw resting and rumen $\mathrm{pH}$ in 20 -min intervals during the $15 \mathrm{~h}$ and 20 min following the afternoon feeding for the $10 \%$ of patterns at the extreme left and the extreme right of the first (groups $1 \mathrm{~A}$ and $1 \mathrm{~B}$ ) and second (groups $2 \mathrm{~A}$ and $2 \mathrm{~B}$ ) axes of the principal component analysis based on the time spent eating and the time spent ruminating during each of the forty-six 20-min intervals following the afternoon feeding obtained in 333 feeding patterns that also had measurements of rumen pH $(22,13$, 14, and 20 patterns, for groups $1 \mathrm{~A}, 1 \mathrm{~B}, 2 \mathrm{~A}$, and $2 \mathrm{~B}$, respectively). 
Table 3. Daily DMI and mean rumen $\mathrm{pH}$, time spent eating and time spent ruminating $15 \mathrm{~h}$ and $20 \mathrm{~min}$ after feeding, when $\mathrm{pH}$ data were available, in 2 groups of goats defined as being the left extreme (group 2A) or the right extreme (group 2B) on the second axis of a principal component analysis of cumulative eating and ruminating time

\begin{tabular}{lcccc}
\hline Item & $\begin{array}{c}\text { Group } \\
2 \mathrm{~A}\end{array}$ & $\begin{array}{c}\text { Group } \\
2 \mathrm{~B}\end{array}$ & $\begin{array}{c}\text { Root mean } \\
\text { square error }\end{array}$ & $P$-value \\
\hline Feeding patterns with pH data (no.) & 14 & 20 & & \\
DMI (g/kg BW) & 44.6 & 44.1 & 8.79 & NS \\
Mean rumen pH & 6.04 & 6.14 & 0.273 & NS \\
Time spent (h:min) & & & & \\
Eating & $04: 06$ & $05: 25$ & $00: 56$ & 0.001 \\
Ruminating & $04: 46$ & $03: 37$ & $00: 39$ & 0.001 \\
\hline
\end{tabular}

of Beauchemin et al. (2003) was induced by changes in forage particle size, whereas the increase in ruminating duration in the present experiment was solely due to individual variability in feeding behavior, as all the animals received a unique diet during the whole experiment. This is in contrast to most feeding behavior experiments that include a comparison between diets. The improvement in ruminal $\mathrm{pH}$ status with increased rumination observed by Beauchemin et al. (2003) might have been more due to the differences in dietary fiber content than to the differences in time spent ruminating per se. Given that similar mean rumen $\mathrm{pH}$ can result from very different rumen $\mathrm{pH}$ patterns, the present analysis confirms that mean rumen $\mathrm{pH}$ cannot be considered as the sole descriptor of ruminal acidosis (Dragomir et al., 2008). Further, the present analysis shows that means over long periods of time of duration of eating, ruminating or rumen $\mathrm{pH}$ are not sufficient to describe what really happened during the studied period. In the present study, analysis of mean eating and ruminating durations and mean rumen $\mathrm{pH}$ would have led to the conclusion that there were differences in duration of rumination, but no differences in rumen $\mathrm{pH}$ between the groups. This was not the case. The present analysis also showed that the use of 1 daily measurement of rumen $\mathrm{pH}$ can lead to misleading conclusions because similar rumen $\mathrm{pH}$ values before feeding can be associated to very different values of rumen $\mathrm{pH} 5$ or $6 \mathrm{~h}$ later. The analysis of time patterns permitted a further interpretation of differences in digestion processes. Although obtaining time-series measurements (patterns) is more demanding than obtaining single measurements, the use of the APEC is easy when the harnesses are well adjusted to the animals and when they are checked every day. The data download is automated and represents a time savings compared with video interpretation. Measuring patterns of $\mathrm{pH}$ implied the involvement of cannulated animals, but in the near future, it will be possible to use long-lasting $\mathrm{pH}$ probes ingested by the animals (Goopy and Woodgate, 2009).

\section{CONCLUSIONS}

The within-day variability in feeding behavior was quite large, even with stall-housed dairy goats receiving the same diet. Although feeding behavior was variable across days for some goats, it was repeatable for others. A continuum between feeding patterns was observed, but with very different patterns of cumulated DMI obtained for the extremes, which resulted in different patterns of rumen $\mathrm{pH}$, even in animals with similar daily DMI and mean rumen $\mathrm{pH}$. This suggests that characterizing animals according to their feeding behavior may provide information on their predisposition to rumen acidosis.

\section{ACKNOWLEDGMENTS}

The authors gratefully acknowledge Alltech Inc. (Lexington, KY) for financial support of this project; and A. Aymard, J. Chevallier, O. Dhumez, G. Durandet, M. Langot, P. Piquerel, A. Severin, and J. Tessier (INRA, UMR791 Modélisation Systématique Appliquée aux Ruminants, Paris and Thiverval-Grignon, France) for their technical assistance during the experiment. We are indebted to N. Friggens and P. Morand-Fehr (INRA, UMR791 Modélisation Systématique Appliquée aux Ruminants, Paris, France)for their useful comments on this paper.

\section{REFERENCES}

Abijaoudé, J. A., P. Morand-Fehr, J. Tessier, P. Schmidely, and D. Sauvant. 2000. Diet effect on the daily feeding behaviour, frequency and characteristics of meals in dairy goats. Livest. Prod. Sci. 64:29-37.

Albright, J. L. 1993. Feeding behavior of dairy cattle. J. Dairy Sci. $76: 485-498$.

Allen, M. S. 1997. Relationship between fermentation acid production in the rumen and the requirement for physically effective fiber. J. Dairy Sci. 80:1447-1462.

Baumont, R., J. P. Dulphy, D. Sauvant, G. Tran, F. Meschy, J. Aufrère, J.-L. Peyraud, and P. Champciaux. 2007. Les tables de la valeur des aliments. Pages 181-286 in Alimentation des Bovins, Ovins et Caprins. Besoins des Animaux-Valeurs des Aliments. Tables INRA 2007. Editions Quae, Versailles, France. 
Beauchemin, K. A., R. G. Kachanoski, G. B. Schaalje, and J. G. Buchanan-Smith. 1990. Characterizing rumination patterns of dairy cows using spectral analysis. J. Anim. Sci. 68:3163-3170.

Beauchemin, K. A., W. Z. Yang, and L. M. Rode. 2003. Effects of particle size of alfalfa-based dairy cow diets on chewing activity, ruminal fermentation, and milk production. J. Dairy Sci. 86:630643.

Brossard, L., M. Fabre, C. Martin, and B. Michalet-Doreau. 2003. Validation of continuous ruminal $\mathrm{pH}$ measurements by indwelling probes. Page 25 in Proc. 26th Conf. on Gastrointestinal Function, Chicago, IL. Department of Animal Science, Michigan State University, East Lansing.

Brun, J. P., S. Prache, and G. Béchet. 1984. A portable device for eating behaviour studies. Pages 1-8 in Proc. 5th Meeting of European Grazing Workshop, Edinburgh, UK. Hill Farming Research Assoc., Midlothian, UK.

Desnoyers, M., G. Béchet, C. Duvaux-Ponter, P. Morand-Fehr, and S. Giger-Reverdin. 2009a. Comparison of video recording and a portable electronic device for measuring the feeding behaviour of individually housed dairy goats. Small Rumin. Res. 83:58-63.

Desnoyers, M., S. Giger-Reverdin, C. Duvaux-Ponter, and D. Sauvant. 2009b. Modeling of off-feed periods caused by subacute acidosis in intensive lactating ruminants: Application to goats. J. Dairy Sci. 92:3894-3906.

Deswysen, A. G., P. Dutilleul, J. P. Godfrin, and W. C. Ellis. 1993. Nycterohemeral eating and ruminating patterns in heifers fed grass or corn silage: Analysis by finite Fourier transform. J. Anim. Sci. 71:2739-2747.

Dragomir, C., D. Sauvant, J.-L. Peyraud, S. Giger-Reverdin, and B. Michalet-Doreau. 2008. Meta-Analysis of 0-8 hours post-prandial kinetics of ruminal $\mathrm{pH}$. Animal 2:1437-1448.

Dulphy, J. P., B. Carle, and C. Demarquilly. 1990. Quantités ingérées et activités alimentaires comparées des ovins, bovins et caprins recevant des fourrages conservés avec ou sans aliment concentré. I. Etude descriptive. Ann. Zootech. 39:95-111.

Dulphy, J. P., and P. Faverdin. 1987. L'ingestion alimentaire chez les ruminants: Modalités et phénomènes associés. Reprod. Nutr. Dev. $27: 129-155$.

Fischer, V., A. G. Deswysen, P. Dutilleul, and J. De Boever. 2002. Ingestive behavior nycterohemeral patterns of dairy cows, at the beginning and at the end of lactation, fed a corn silage based diet. R. Bras. Zootec. 31:2129-2138.

Goopy, J. P., and R. Woodgate. 2009. Short-term validation of a rumen indwelling $\mathrm{pH}$ meter. Page 175 in Recent Advances in Animal Nutrition-Australia. 20th Biennial Conference. University of New England, Armidale, NSW, Australia
Heinrichs, A. J., and H. R. Conrad. 1987. Measuring feed intake patterns and meal size of lactating dairy cows. J. Dairy Sci. 70:705711.

ISO. 1983. ISO 6496. Animal Feedingstuffs. Determination of moisture and other volatile matter content. International Organisation for Standardisation, Geneva, Switzerland.

Jarrige, R., J. P. Dulphy, P. Faverdin, R. Baumont, and C. Demarquilly. 1995. Activités d'ingestion et de rumination. Pages 123-181 in Nutrition des ruminants domestiques. Ingestion et digestion. R. Jarrige, Y. Ruckebusch, C. Demarquilly, M. H. Farce, and M. Journet, ed. Institut National de la Recherche Agronomique, Paris, France.

Krause, K. M., and G. R. Oetzel. 2006. Understanding and preventing subacute ruminal acidosis in dairy herds: A review. Anim. Feed Sci. Technol. 126:215-236.

Maekawa, M., K. A. Beauchemin, and D. A. Christensen. 2002. Effect of concentrate level and feeding management on chewing activities, saliva production, and ruminal $\mathrm{pH}$ of lactating dairy cows. J. Dairy Sci. 85:1165-1175.

Murphy, M. R., R. L. Baldwin, M. J. Ulyatt, and L. J. Koong. 1983 A quantitative analysis of rumination patterns. J. Anim. Sci. $56: 1236-1240$

Nocek, J. E. 1997. Bovine acidosis: Implications on laminitis. J. Dairy Sci. 80:1005-1028.

Oetzel, G. R. 2000. Clinical aspects of ruminal acidosis in dairy cattle. Page 46-53 in Proc. 33rd Annual Conf., Am. Assoc. Bovine Practitioners, Rapid City, SD.

Owens, F. N., D. S. Secrist, W. J. Hill, and D. R. Gill. 1998. Acidosis in cattle: A review. J. Anim. Sci. 76:275-286.

Putnam, P. A., R. Lehmann, and R. E. Davis. 1966. Feed intake and salivary secretion by steers. J. Anim. Sci. 25:817-820.

Sauvant, D., and S. Giger-Reverdin. 2007. Empirical modelling by meta-analysis of digestive interactions and $\mathrm{CH} 4$ production in ruminants. Pages 561-563 in 2nd EAAP Int. Symp. on Energy and Protein Metabolism and Nutrition. Wageningen Academic Publishers, Wageningen, the Netherlands.

Vermorel, M. 1988. 3. Nutrition énergétique. Pages 57-74 in Alimentation des Bovins, Ovins et Caprins. R. Jarrige, ed. Institut National de la Recherche Agronomique, Paris, France.

Welch, J. G., and A. M. Smith. 1971. Physical stimulation of rumination activity. J. Anim. Sci. 33:1118-1123.

Woodford, S. T., and M. R. Murphy. 1988. Effect of forage physical form on chewing activity, dry matter intake, and rumen function of dairy cows in early lactation. J. Dairy Sci. 71:674-686. 